\title{
Representações sociais de saúde bucal entre mães no meio rural de Itaúna (MG), 2002
}

\author{
A social representation study of oral health among \\ mothers in rural areas, Itaúna (MG), 2002
}

Mauro Henrique Nogueira Guimarães de Abreu 1

Isabela Almeida Pordeus 2

Celina Maria Modena 3

\footnotetext{
1 Departamento de Odontologia da Universidade Estadual de Montes Claros. Rua Dr. Rui Braga, s.n., Vila Mauricéia, 39401-098, Montes Claros MG. mauroh@teacher.com

2 Departamento de Odontopediatria e Ortodontia da UFMG.

3 Departamento de Medicina Veterinária Preventiva da UFMG.
}

Abstract The study evaluated social representation on oral health-illness process between 29 scholarship's mothers in rural areas from Itaúna, in 2002. Semi-structured interviews were transcripted and content analysis was developed. The results have showed that social representation of health-illness was associated with food intake and medical service utilization. Discourse on oral health-illness process was related to dental hygiene and diet rules. Dental caries were an inevitable experience, but tooth loss was not. Despite material conditions of life in rural area have not enabled favorable oral health practices, these mothers were considered responsible for their children oral health care. This contradicted life has caused negative feelings (as guilty) and, consequently, bad quality of life. Respondents have had information about oral home care and they desired to "take care of children well". However, a complex net of social, economic and cultural factors has not favored health promotion. Planning public oral health actions should take in account not only quantitative epidemiological data but social representation of oral health.

Key words Qualitative research, Epidemiology, Social representation, Oral health
Resumo Análise das representações sociais sobre o processo saúde-doença bucal entre 29 mães de escolares residentes no meio rural de Itaúna, em 2002. As entrevistas semi-estruturadas foram transcritas e a análise de conteúdo foi desenvolvida. A análise mostra que as representações sociais sobre saúde-doença estão vinculadas à alimentação e utilização de serviços médicos. Em relação ao processo saúde-doença bucal, identifica-se um discurso associado às normas odontológicas de higiene e dieta. A cárie dentária é vista como uma experiência inevitável, mas a perda dentária, não. Apesar de as condições materiais de vida no meio rural dificultarem a adoção de práticas consideradas favoráveis à saúde bucal, essas mulheres são cobradas em relação ao trabalho de cuidar dos filhos. Essa vivência contraditória causa sentimentos negativos (culpa) e, como conseqüência, queda na qualidade de vida nessa população. $\mathrm{Na}$ realidade de vida das entrevistadas, verifica-se que, apesar de as mesmas apresentarem informações sobre o cuidado bucal e desejarem "cuidar dos filhos direito", uma complexa rede de fatores sociais, econômicos, culturais etc., não favorece a promoção de saúde. O planejamento das ações de saúde bucal coletiva deveria levar em consideração não somente dados epidemiológicos quantitativos, mas também as representações sociais sobre saúde bucal.

Palavras-chave Pesquisa qualitativa, Epidemiologia, Representação social, Saúde bucal 


\section{Introdução}

Tradicionalmente, o diagnóstico das condições sanitárias de grupos populacionais é feito por meio de indicadores numéricos, utilizando-se o referencial teórico da epidemiologia clássica. Essa abordagem tem grande importância para o planejamento das ações de saúde coletiva. No entanto, nas últimas décadas, diversos autores constataram a necessidade da utilização de outros métodos para se avaliar o processo saúdedoença em grupos populacionais. Esses questionamentos são realizados uma vez que não se identifica, por exemplo, uma coincidência entre as necessidades de saúde bucal nos estudos de prevalência e incidência e aquelas necessidades percebidas pelas pessoas. Além disso, os conceitos sobre saúde/doença são fortemente influenciados por valores culturais. Desta forma, quando se necessita avaliar um universo de significados, desejos, aspirações, motivos, valores, o método estatístico não consegue abarcar tais dimensões com a profundidade pretendida, sendo necessária uma abordagem da qualidade do fenômeno, através do método qualitativo. Assim, o planejamento não deveria se reduzir a produção de dados e indicadores externos aos sujeitos que conferem significado às ações de saúde. Não há, entretanto, uma negação da relevância das avaliações quantitativas, mas sim, a evidência da complementaridade dessas metodologias (Marsiglia et al., 1990; Minayo, 1994; Perini, 1998; Rouquayrol \& Goldbaum, 1999; Sheiham, 2000; Vargas, 2002).

Considerando a importância da avaliação dos aspectos qualitativos do processo saúdedoença, o conceito de representações sociais tem sido cada vez mais utilizado na área da saúde pública e da epidemiologia (Paixão, 1986; Minayo, 1993; Andrade, 1996; Perini, 1998; Mallison, 2002). Especificamente, em relação à representação social de saúde bucal, alguns estudos, também, foram desenvolvidos no Brasil (Bernd et al., 1992; Wolf, 1998; Carneiro, 2001; Mendonça, 2001; Nations \& Nuto, 2002; Fernandes, 2002; Vargas, 2002). No entanto, a avaliação das representações sociais sobre saúde bucal entre populações rurais tem sido ainda mais escassa do que nas sociedades urbanas. É importante, também, avaliar se sociedades rurais apresentam representações sociais diferentes daquelas que se conhece em estudos já realizados no meio urbano. Essa lacuna do conhecimento pode dificultar a realização de um correto diagnóstico sobre "as visões de mundo" de grupos sociais a quem se destinam possíveis intervenções coletivas em saúde bucal. Neste sentido, duas possibilidades podem ocorrer. A primeira é a realização de programas ou medidas coletivas alienantes (Paixão et al., 1995). Outra possibilidade, talvez a mais comum de acordo com alguns estudos (Andrioni et al., 1969; Bijella \& Bijella, 1970; Carvalho de Oliveira \& Tavares, 1981; Makowiecky \& Silva, 1981; Marcos et al., 1977; Marques et al., 1986; Dini \& Silva 1994; Furtado et al. 1999; Sampaio et al., 2000), seria a não implementação de qualquer medida de saúde bucal coletiva para essa população.

Além disso, a evolução do conceito do processo saúde-doença culminou, em épocas mais recentes, na associação do mesmo com qualidade de vida. A Organização Mundial de Saúde (OMS) define qualidade de vida como a percepção do indivíduo, de sua posição na vida, no contexto da cultura e do sistema de valores em que vive e em relação aos seus objetivos, expectativas, padrões e preocupações (WHOQOL, 1995). $\mathrm{Na}$ qualidade de vida, três dimensões são consideradas importantes: capacidade funcional (funções sociais, físicas, emocionais e intelectuais), percepção de bem-estar (satisfação com a vida e condição de saúde) e sintomas físicos (de doenças) (Reisine, 1988). Os conceitos anteriores nos permitem concordar com Ruffino Neto (1994), quando o mesmo afirma que a qualidade de vida deveria ser adjetivada mais pelas pessoas do que pelos cientistas que observam as mesmas.

Em relação ao processo saúde-doença no âmbito de famílias, alguns autores colocam claramente a liderança da mãe nessas questões (Pordeus, 1991; Tezoquipa et al., 2001; Fernandes, 2002). Assim, avaliar as representações sociais sobre o processo saúde-doença e, por conseqüência, o que é qualidade de vida entre mães torna-se importante fator definidor de políticas de saúde neste grupo. Além disso, através da abordagem qualitativa, pode-se avaliar se as condições de saúde bucal interferem na qualidade de vida da família e como tal processo ocorre.

Desta forma, o presente estudo objetivou identificar e analisar as representações sociais do processo saúde-doença bucal entre mães de escolares no meio rural de Itaúna (MG), em 2002. 


\section{Metodologia}

\section{População de estudo}

A população de estudo foi composta por 29 mães de escolares do ensino infantil e fundamental do município de Itaúna (MG). Dois pais participaram das entrevistas por estarem em suas residências no momento do trabalho de campo e por demonstrarem o desejo de participar do estudo.

Itaúna é uma cidade localizada na Mesorregião Oeste do Estado de Minas Gerais, com uma população estimada em 76.862 habitantes, sendo que destes, 5.092 são moradores do meio rural. De acordo com dados da Prefeitura, todas as crianças do meio rural estão matriculadas na rede pública de ensino. Há dezenas de comunidades rurais no município, mas apenas oito têm, atualmente, Escola Municipal em funcionamento. As crianças residentes em comunidades sem escola são transportadas até a comunidade mais próxima pelo setor público local. A assistência à saúde, através do Sistema Único de Saúde (SUS) local, é realizada em quinze Postos de Saúde no meio urbano e cinco, nas comunidades rurais. Há, ainda, um hospital filantrópico, conveniado com o SUS. O programa de saúde bucal realiza atividades coletivas de educação em saúde e atendimento odontológico individual no meio urbano. No meio rural há as denominadas Equipes de Prevenção Rural Odontológica, que realizam atendimento individual de atenção básica, geralmente uma vez ao ano, aos escolares e à comunidade do meio rural. O programa odontológico do meio rural envolve, ainda, entrega de escovas e dentifrícios e orientação de escovação para os escolares (Prefeitura da Cidade de Itaúna - PCI, 2000).

A Secretaria Municipal de Educação forneceu a relação dos alunos matriculados no ano de 2002, a partir da qual foram selecionadas as mães para a realização da entrevista. Em relação ao número de entrevistas realizadas, a pesquisa qualitativa não se preocupa com o número de entrevistados, um vez que esse método trabalha com amostras, em geral, pequenas e intencionalmente selecionadas (Santos, 1999). Minayo (1993) ainda afirma que em uma pesquisa qualitativa a preocupação maior é com a abrangência da compreensão. A autora indica que para a definição de uma amostra ideal deve-se definir o grupo social mais relevante para as entrevistas, e não finalizar a inclusão de en- trevistados enquanto não houver o delineamento do quadro empírico da pesquisa. Inicialmente foi planejada a realização de, pelo menos, duas entrevistas em cada uma das oito áreas de abrangência das escolas. No entanto, foram realizadas 29 entrevistas, considerando os critérios apontados anteriormente por Minayo (1993). Apesar de a seleção dos participantes não ter sido realizada utilizando o método probabilístico, verificou-se que não havia diferenças estatisticamente significantes entre essa amostra e o universo avaliado em um estudo epidemiológico quantitativo realizado anteriormente $(\mathrm{p}>0,05)$ para as variáveis renda familiar, ocupação da mãe e do pai, escolaridade da mãe e do pai, idade do filho e índices de cárie dentária em ambas as dentições. O consumo de água tratada, entretanto, foi mais freqüente $(\mathrm{p}<0,05)$ entre a amostra $(\mathrm{n}=29)$ do que no universo (Abreu, 2004).

\section{A entrevista semi-estruturada}

A orientação metodológica desta pesquisa foi baseada em Bardin (1977), Triviños (1987) e Minayo (1993).

Inicialmente foram feitos contatos com a administração central do município através do prefeito e dos secretários municipais de saúde e educação. Em um segundo momento, foi realizada uma reunião com os líderes das comunidades rurais. Houve, ainda, reuniões com os responsáveis pelos escolares, em cada uma das escolas municipais. Em todos os momentos, o objetivo da pesquisa, os métodos de entrevista e a forma de divulgação dos mesmos, dentre outros, foram apresentados. Essa etapa é considerada fundamental por Minayo (1993), uma vez que se estabelece os primeiros contatos, permitindo o fluir da rede de relações. Somente após todos esses contatos é que, no primeiro semestre de 2002, foram realizadas as entrevistas.

As entrevistas semi-estruturadas são aquelas que partem de certos pressupostos iniciais, mas o entrevistado pode responder livremente. Todas as entrevistas foram realizadas, gravadas e transcritas pelo mesmo pesquisador. As quatro unidades de contexto eram: processo saúde/doença, processo saúde-doença bucal, cavidade bucal e qualidade de vida, cuidados caseiros com a saúde bucal. No entanto, o interesse central foi conhecer as representações sociais sobre saúde/doença bucal e suas possíveis implicações na qualidade de vida da família. 


\section{Análise dos dados}

Após a transcrição das entrevistas, passouse para a análise de conteúdo (Bardin, 1977; Minayo, 1993). Essa etapa envolveu a organização do material de acordo com as unidades de contexto, elaboração das categorias segundo a literatura consultada, experiência pessoal do pesquisador e, finalmente, a consolidação ou redefinição das categorias objetivando direcionar as discussões e conclusões sobre a representação social sobre saúde/doença bucal e sua influência na qualidade de vida. A apresentação das falas transcritas respeitou a grafia e a sintaxe utilizada pelos entrevistados.

\section{Comitê de ética}

Por se tratar de um estudo que envolve seres humanos, o mesmo foi enviado para o Comitê de Ética em Pesquisa da Universidade Federal de Minas Gerais, tendo sido aprovado em 2/10/2001 (parecer número ETIC 147/01).

\section{Resultados e discussão}

Alguns indicadores quantitativos serão brevemente apresentados para se conhecer a situação econômica e social do grupo estudado. As famílias participantes da entrevista apresentavam renda média igual a $\mathrm{R} \$ 371,03( \pm 226,35)$. Pouco mais da metade dos pais $(50,7 \%)$ possuía ocupação rural não-agrícola. As mães, na sua grande maioria $(79,31 \%)$, eram donas de casa. A escolaridade média, respectivamente para pais e mães, era de 3,86 $( \pm 2,2935)$ e 4,07 $( \pm 2,3435)$. Um grande número de residências (69\%) apresentava água de abastecimento do Serviço Autônomo de Água e Esgoto municipal (água clorada). A idade média das crianças foi igual a 7,38 $( \pm 1,9535)$. A prevalência de cárie para esses indivíduos, considerando ambas as dentições, foi igual a 82,14\%, ou seja, 391 escolares apresentavam pelo menos um dente com experiência da doença. Desta forma, apenas 17,86\% das crianças eram livres de cárie. As crianças apresentavam índices CPOD (número de dentes permanentes cariados, perdidos e restaurados) e Ceod (número de dentes decíduos cariados, com extração indicada ou restaurados) médios iguais a 0,84 e 3,66 , respectivamente.

\section{Representações sobre saúde/doença}

Em um primeiro momento, procurou-se entender as representações dos entrevistados sobre o processo saúde/doença.

Tal processo não pode, ainda nos dias de hoje, ser considerado apenas através dos seus aspectos biológicos, mas sim um fenômeno intimamente relacionado com as características de cada sociedade, na qual o doente é um personagem social. Existe, assim, uma ordem de significações culturais nos fenômenos do adoecimento humano (Minayo, 1993; Perini, 1998).

No presente estudo, um dos aspectos que aparecem intimamente ligados à idéia de saúde é a questão da alimentação.

A base da alimentação interfere muito no dia-a-dia da gente, mesmo no retardar, na vida futura. (...) Apesar que a gente não consegue ter uma boa alimentação não. (Entrevistada n. 17)

Esses resultados reforçam achados de outras autoras como Loyola (1984), Paixão (1986), Minayo (1988). Essas autoras mostram que a representação social sobre saúde está intimamente ligada à idéia de força. Força que será utilizada no trabalho e que a comida mantém e estimula. A alimentação é um elemento essencial na manutenção da força de trabalho. No meio rural de Itaúna, considerando que a inserção produtiva dos chefes de família submete os sujeitos a um uso intenso do corpo, a sua manutenção é de grande importância. No entanto, é recorrente a frustração de não se conseguir uma alimentação adequada. O fato de estarmos lidando com indivíduos que moram no meio rural não exclui a possibilidade de os mesmos não apresentarem condições objetivas de subsistência da sua família. É o que nos conta uma entrevistada, cujo marido apresenta uma ocupação rural não-agrícola com renda familiar mensal igual a $\mathrm{R} \$ 350,00$, sobre o que é saúde

(...) alimentação boa, mas a gente não tem (risos). Ainda mais uma casa com quatro. A gente leva mais ou menos, né. (Entrevistada n. 21)

O corpo tem sido, desde a divisão social do trabalho e do surgimento das classes e do Estado, o "gerador de bens" por excelência para aqueles que têm no corpo a única propriedade. Desta forma, o corpo é considerado, numa sociedade capitalista, forma de mercadoria e geradora de bens para os donos dos meios de produção. Assim, "ter saúde" é ter disposição para trabalhar, para conseguir as coisas, né. Então, não tem jeito na vida. (Entrevistada n. 19) 
Quando a doença impede a pessoa de trabalhar, a mesma perde a única forma de sobrevivência: o seu corpo. Essas representações mostram uma realidade na qual o corpo é a única forma de sobrevivência para uma grande maioria da população (Paixão, 1986; Breilh, 1991; Minayo, 1993). Como também afirma uma outra entrevistada: Igual esse meu filho mais velho, para ele ir ao médico ele tem que tá ruim demais (...), senão não vai. (Entrevistada n. 13)

Algumas entrevistadas ainda relacionam saúde com a utilização da tecnologia médica (como o medicamento) ou do serviço de saúde, sempre como uma visão biomédica. Esse fato mostra que a população se apropria do modelo tido como hegemônico na área da saúde para o qual o ser humano é considerado uma máquina e a doença, um mau funcionamento dos mecanismos biológicos. O papel do médico, nesta lógica mecanicista, consiste em intervir física ou quimicamente para consertar um defeito de funcionamento dessa "máquina” (Capra, 1989).

Saúde para mim é ter que ir ao médico para corrigir alguma coisa, para ver se tá certo, né. (Entrevistada n. 7)

Outras mães afirmam que saúde depende de um meio ambiente favorável

Para mim saúde é você viver, assim, num lugar bom, sabe. Primeiro, ter um lugar bom para se viver, água boa, né, esgoto, boa alimentação, sono bom, tranqüilo. Saúde para mim quer dizer tudo isso. (Entrevistada n. 3)

Essa visão, aparentemente mais ampliada da saúde, escamoteia as relações sociais de produção capitalista. É como se o acesso à água, esgoto, sono bom não estivessem ligados às características do sistema capitalista que se baseia no lucro, nas contradições entre os que produzem a riqueza e os que dela se apropriam, entre a harmonia da natureza e seu uso predatório com finalidade econômica imediatista (Minayo, 1993).

\section{Processo saúde/doença bucal}

A partir dessas representações mais gerais sobre saúde, procuramos entender as representações sociais do processo saúde/doença bucal nesse grupo.

O discurso dominante das entrevistadas revelou que o adoecimento bucal está associado às normas de higiene e dietéticas, ou seja, saúde bucal não é considerada um estado, mas a atividade de cuidar do corpo (Paixão et al., 1995).

Saúde também é o cuidado da pessoa; é a escova e o creme dental. Porque se não tiver esses e o fio dental também, em um instante os dentes vão estar todos estragados. (Entrevistada n. 2)

O cuidado com o corpo é atividade diretamente relacionada à cultura e à organização psíquica dos sujeitos (Rodrigues, 1979). O saber feminino sobre o cuidado em saúde é construído socialmente, sendo influenciado pelo seu contato com os serviços de saúde, sua própria experiência no âmbito doméstico, transmissão de conhecimento por antepassados e através dos meios de comunicação (Tezoquipa et al., 2001). Sem se opor à necessidade universal de cuidar do corpo, não se pode deixar de afirmar também que, especificamente na odontologia, há uma ideologia por trás dessa questão e que merece ser comentada. Na medida que as normas de higiene são prescritas para toda a sociedade, as pessoas adoecem por culpa ou "descuido da pessoa”, como mostram vários estudos qualitativos em saúde bucal. Por conseqüência, o grande responsável pelo adoecimento bucal é o próprio indivíduo (Bernd et al., 1992; Carneiro, 2001; Mendonça, 2001; Vargas, 2002).

O que é ter saúde? Eu acho que tem que ter higiene própria dos dentes, cuidar deles. E, no geral, eu acho que é higiene. Se a pessoa não tiver higiene dos dentes, não vai ter saúde bucal, né. (Entrevistada n. 29)

Essas representações de saúde bucal, como sendo algo fundamentalmente endógeno e de responsabilidade individual, pressupõem a existência de uma sociedade equilibrada e passível de controle pela vontade individual (Minayo, 1993). No entanto, a nossa estrutura social, longe de ser igualitária, impossibilita, muitas vezes, que as escolhas saudáveis sejam as mais fáceis de serem adotadas (WHO, 1996; Moysés \& Watt, 2000; Watt, 2002).

Parece, pelo que foi comentado nos últimos parágrafos, que estamos diante de situações opostas. De um lado, o trabalho de cuidar, atividade inerente ao ser humano; e de outro, as dificuldade impostas pela sociedade para a realização de tais atividades. No entanto, a prática de atividades educativas em saúde de cunho problematizador, e que consigam fazer um elo entre o trabalho de cuidar e os aspectos sociais, pode ser um caminho para a solução de tais questões (Roux, 1994; Kemm, 2003; Pereira, 2003).

Especificamente em relação aos hábitos dietéticos, alimentos considerados "doces" como chicletes, balas, chocolates, ou nos dizeres dos próprios entrevistados, "os imbondos" (denominação dada pelos moradores do meio rural a alimentos como chiclete, bala, chocolate, etc.) 
são os mais danosos. As entrevistadas identificam a associação entre certos alimentos e a cárie dentária. Os entrevistados explicam que a consistência dura das balas desgasta os dentes. O pegajoso do chiclete, por outro lado, pode remover restaurações.

Principalmente o chiclete que prejudica. $\mathrm{Ob}$ tura um dente e fica (mãe imita o som de mastigar um chiclete). Cai a obturação do dente. As balas também... fica mastigando muito. É ruim demais para os dentes. (Entrevistada n. 21)

A consistência dos alimentos com sacarose (pela sua manutenção na cavidade bucal e não pelo desgaste dentário) envolve uma maior ou menor cariogenicidade (Gustafsson et al., 1954; Auad \& Pordeus, 1999). Pode ser que o discurso dos profissionais de saúde bucal, que freqüentam regularmente o meio rural, esteja sendo reinterpretado (Boltanski, 1989). Nesta reinterpretação, os membros de classes populares consideram mais os aspectos do cotidiano, como é o caso do desgaste das restaurações, do que os aspectos biológicos envolvidos com a ação da sacarose. Essa reinterpretação não deve ser entendida como demérito algum para esse grupo. Por outro lado, o demérito estaria do lado dos profissionais de saúde, caso os mesmos não respeitassem tais representações, adotando uma atitude etnocêntrica, segundo a qual todo conhecimento produzido fora do "conhecimento oficial da saúde" é erro, ignorância e deve ser expurgado (Minayo, 1994).

Os alimentos que são considerados benéficos para a saúde bucal são principalmente o leite, o ovo, as verduras. Brindle et al. (2000), no seu estudo qualitativo realizado no meio rural da África, também identificaram o leite como um alimento protetor para os dentes.

Esses alimentos são considerados importantes, pelas mães itaunenses, por conter cálcio, vitaminas e serem "fortes". Alguns alimentos são fortes inclusive para proteger a saúde contra o efeito dos "imbondos".

De manhã cedo elas sempre tomam ovo quente. A gente dá o errado e corrige com o certo. Então, assim, tipo assim, contra-balanceia (Entrevistada n.1).

Eu acho que os dentes vai muito da alimentação também. A verdura, um leite, um ovo. Pelo menos eu tenho essa impressão que ajuda. Menino que fica muito sem vitamina no corpo, vitamina natural, o dente dele fica fraquinho (Entrevistada n.18).

Essa noção de alimento "forte" em oposição ao alimento "fraco", ou que deixa o dente "fra- quinho", foi explicada por Loyola (1984). Na avaliação da autora, os alimentos valorizados pelas classes populares são aqueles que "sustentam e dão força". Desta forma, parece que as representações sociais sobre alimentação e saúde bucal neste grupo estudado refletem também tais valores.

Há, ainda, uma certa resistência aos alimentos industrializados, considerados aqueles que apresentam "muita química". O refrigerante, o "doce comprado" são vistos como perigosos. Indivíduos que estão em contato bem próximo com a produção caseira de alimentos parecem resistir ao processo de industrialização destes bens de consumo. Além disso, seria uma incoerência para essa população considerar que o alimento produzido pela própria mãe fosse identificado como símbolo de algo danoso para o seu filho.

Esses doce natural que a gente faz, a gente faz eles com o quê? Açúcar e leite. Agora esses comprado têm muita química nele. Esse trem que fica conservado ali anos. Eu acho que isso prejudica. (Entrevistada n.18)

A cárie dentária afeta a maioria dos filhos das entrevistadas. Assim, a doença é, para a maioria dos sujeitos, uma experiência inevitável. Esse achado confirma outros estudos (Kwan \& Holmes, 1999; Nations \& Nuto, 2002). Mesmo adotando as normas de higiene consideradas corretas, a doença continua aparecendo e esse é o momento da assistência odontológica.

(...) o que eu acho mais necessário é a escovação (...) isso ajuda muito. Mas mesmo fazendo isso, às vezes ainda acaba estragando, né. Aí então é necessário, como se diz, ir para o dentista. (Entrevistada n. 2)

Dados recentes mostram que os serviços de saúde bucal tiveram uma participação muito modesta para o declínio da cárie dentária (Nadanovsky, 2000). O mesmo autor ainda comenta que os serviços de saúde bucal têm, dentre outros, o papel de tranqüilizar, prover tratamento de emergência, cuidar e confortar. A população rural de Itaúna percebe a importância do serviço de saúde bucal nesses aspectos.

Ainda em relação à cárie, apesar de ser considerada inevitável, a maioria das entrevistadas não se conforma com a perda dentária e, principalmente, com o edentulismo, situação que eles conhecem de perto.

Entrevistador: Você acha possivel manter os dentes da gente até o final da vida?

Entrevistada n.17: Eu acho que sim. Eu acho que é. Apesar que (...) eu não sei se você já repa- 
rou, a maioria dos idosos não tem os dentes naturais. Ou não tem nenhum ou tem poucos. Mas hoje, com os cuidados que tem sido feitos, com as prevenções, eu acho possível. Eu quero pelo menos que ela chegue na velhice com essa minha boca.

- Não, não é normal perder, porque se tem conserto, vamos arrumar. Se não tiver como pagar de uma vez, parcela, sabe. Faz qualquer coisa mas arruma. (Entrevistada n. 27)

As perdas dentárias estão fortemente associadas, no Brasil, a questões sociais e econômicas (Guimarães \& Marcos, 1996). A população rural de Itaúna, desta forma, conhece bem essa realidade, mas não se conforma com ela. A perda dentária relaciona-se com componentes psíquicos e sociais importantes. A nossa sociedade atual "supervaloriza" a aparência em detrimento de outros valores. Assim, a perda de dentes, que pode afetar o sorriso considerado esteticamente agradável, torna as pessoas vulneráveis a sentimentos de inferioridade, rejeitadas e inseguras. A perda dentária impõe às pessoas uma situação social desfavorável (Wolf, 1998; Vargas, 2002). No meio rural de Itaúna verifica-se um confronto entre a realidade vivida (na qual há pessoas perdendo dentes) e a realidade almejada (na qual a perda de dentes não esteja mais presente). Esse confronto pode ser um aspecto importante para que mudanças aconteçam.

Outro aspecto abordado nas entrevistas foi sobre as representações das mães em relação ao papel das águas de abastecimento na saúde bucal. Sabe-se que uma das grandes conquistas em termos de saúde bucal no século 20 foi a incorporação de fluoretos nas águas de abastecimento (Oliveira et al., 1995). Assim, ainda que no meio rural de Itaúna as águas de abastecimento não recebam tal tratamento, as entrevistas envolveram tal questão. As queixas das mães em relação ao sabor, à cor e, principalmente, ao cheiro das águas foram freqüentes.

(...) a água é muito suja, né. Principalmente tem hora que tá com um cloro danado, um cheiro forte na água. Mas isso é no geral, né. As comidas... acho que o povo tá tendo muita doença, as verduras tá tendo muito agrotóxico, as águas também, tem cloro demais. (Entrevistada n.11)

Entrevistador: (...) o cloro ajuda ou prejudica?

Entrevistada n. 16: Ah eu não sei não. Eu tive experiência que as vasilhas da cozinha fica preta, os dentes pode ficar também, não? Eu não sei, porque as vasilhas fica com um cabo escuro. Eu tive experiência com isso. Deve fazer mal, não sei. Ou fazer mal, mas bem. Eu não sei como deve pensar não. Mata os micróbios também. Dá pureza na água. Só que tem que... às vezes pode prejudicar para gente, né.

Entrevistador: Sei. Ajuda por um lado mas pode prejudicar por outro.

Entrevistada n. 16: (...) Por dentro da gente deve fazer um estrago que nem nas vasilhas de aluminio.

Essa é a percepção hegemônica entre os moradores do meio rural que têm acesso à água tratada pelo poder público municipal. A relação entre cheiro e aparência "ruim" da água e sentimentos negativos podem estar associados com as representações sociais das doenças, que estão historicamente associadas com cheiros/odores considerados desagradáveis (Sevalho, 1993). Além disso, um dos sentidos mais utilizados pelo homem na sua vida cotidiana é o olfato. A atitude dos homens diante das sensações olfativas e dos conhecimentos que chegam através dessa via é, muitas vezes, de desconfiança (Rodrigues, 1979).

Em relação à questão da água tratada, é necessário que o poder público reflita sobre as representações sociais dessa população. Desta forma, o planejamento de ações coletivas em saúde deve levar em consideração não somente a eficácia da intervenção (Mota, 1999; Amaral et al., 2003), mas sobretudo as percepções que os grupos populacionais têm da sua realidade.

A associação entre medicamentos fortes, como o antibiótico, e "dente estragado" apareceu neste estudo. Os entrevistados foram questionados sobre a razão dessa percepção. As seguintes questões apareceram:

Ele faz o dente ficar fraco, né. Enfraquece o dente. Agora o por quê? É a química. Agora qual química que faz isso, eu não vou saber te explicar (riso). (Entrevistada n. 24)

Eu acho que é porque ele é forte, né. Ele é bem forte. (Entrevistada n. 28)

Entrevistador: Você acha que os " 800 ” (valor encontrado no resultado de exame laboratorial do filho quando o mesmo apresentou reumatismo, na fala de uma mãe) de reumatismo no sangue deixou o dente mais fraco?

Entrevistada n. 19: Uai, deixa, né. Os ossos, tudo, né. Ele ficava aquele menino mole, né. Não gostava de brincar, uma hora deitado, uma hora no braço. É difícil mesmo (...).

A oposição entre medicamentos "fortes" e "fracos" foi mostrada nos estudos de Boltanski (1989) e Loyola (1984). Esses autores afirmam que os membros de classes populares percebem os fármacos a partir de sua eficácia, sendo que os antibióticos são considerados "fortes”. Loyo- 
la (1984) ainda afirma que os medicamentos "fortes" apresentam efeitos adversos em outras partes do corpo.

Além disso, Ferreira (2002) mostra que a associação entre antibiótico e dentes fracos, pelos seus entrevistados, está associada ao efeito do antibiótico sobre os microrganismos. $\mathrm{Na}$ percepção dos seus entrevistados, na medida em que os antibióticos destroem os "microrganismos fracos”, eles também podem destruir os dentes.

Os antibióticos não exercem nenhum efeito causal sobre a cárie dentária. No entanto, duas considerações merecem ser apresentadas. A utilização em um passado não muito distante do antibiótico tetraciclina em crianças levou ao aparecimento de manchamentos nos dentes, os quais podem ser percebidos pela população como cárie. Em segundo lugar, a apresentação de certos antibióticos pode conter sacarose (as suspensões, por exemplo). Desta forma, esquemas posológicos de, por exemplo, 6 em 6 horas podem aumentar o risco de cárie do indivíduo (Wannmacher \& Ferreira, 1999; Neville et al., 2002). Como afirma uma mãe:

Eu não sei. Eu ouvi falar assim. Eu também nem sei se é verdade, né, que o antibiótico pode estragar os dentes. Deve ser porque antibiótico é doce, geralmente o antibiótico é até gostoso de tomar, é docinho. Deve ser por isso, não sei também. (Entrevistada n. 26)

\section{Saúde bucal e qualidade de vida}

A relação entre saúde bucal e qualidade de vida já foi mostrada em vários estudos epidemiológicos quantitativos (Reisine, 1988; Locker et al., 2000) e em alguns qualitativos (Wolf, 1998; Vargas, 2002). No entanto, avaliações do impacto da saúde bucal na vida de famílias rurais não têm sido exploradas pela literatura nacional. Na presente pesquisa, os pressupostos iniciais eram que problemas bucais da criança poderiam interferir na rotina da família rural, podendo ser um dos fatores de impacto na qualidade de vida das pessoas.

Através da análise realizada, observou-se que as mães apresentam uma grande preocupação com a saúde bucal atual, bem como o impacto que essa terá no futuro do filho. São freqüentes, ainda, as considerações de que no passado a assistência odontológica era mais excludente e de pior qualidade. Os entrevistados parecem não querer para seus filhos as mesmas experiências que eles consideram negativas, se- não vejamos:

Igual eu não cuidei dos meus (dentes) quando eu era mais nova que trabalhei só na roça com meu pai. Nesse tempo não vinha dentista olhar os dentes. Então acabou que eu não cuidei dos meus. Agora como eu tenho os meus meninos, sempre eu falo com eles que eles tem que cuidar, porque depois, né, fica ruim. (Entrevistada n.12)

Desta forma, algumas considerações sobre o papel do filho em uma família serão apresentadas.

Quando um filho é gerado, há uma modificação na identidade dos genitores. Um imaginário repleto de esperança é construído pelos pais. Somente um estado de extrema miséria ou incerteza (presente, por exemplo, em uma guerra) pode retirar das pessoas o sonho de um futuro melhor para os filhos (Vicente, 1998). Além disso, o ambiente familiar deve oferecer confiança e suporte à criança, sendo o núcleo primordial que acolhe a mesma. Os pais transmitem aos filhos suas fantasias, seus conhecimentos, suas experiências, moldando-os de acordo com suas condições psíquicas e com o grau de maturidade em que se encontram. A influência dos antecessores dos pais explica boa parte do que se passa na relação familiar (Cavalini, 2000).

Assim, especificamente no meio rural de Itaúna, algumas condições desfavoráveis de saúde bucal podem gerar sentimentos nas mães, podendo ser consideradas um dos fatores que interferem na qualidade de vida das mesmas. Deixemos uma entrevistada ilustrar essa discussão.

Entrevistador: Me conta uma coisa, (nome da mãe), a (nome da filha) é que teve dor. Como é que foi o seu sentimento em relação à dor (de dente)?

Entrevistada n. 27: A gente chora. Mãe é assim, tudo que tem no filho, ela quer para ela, entendeu? Se o filho está sentindo uma dor, a gente quer sentir para ele. A (filha) quando era bebezinha de colo, o marimbondo ferroou o dedinho dela. Ela chorava tanto e eu chorei junto com ela. Porque ela era pequenininha, tinha três, quatro meses. E ela chorou muito e eu pensei por que esse marimbondo não picou eu. Por que ela tava no meu colo e foi logo no dedinho dela? Porque ele não picou o meu dedo e não o dela. Então tudo, as dores que os filhos sentem, a gente quer para a gente. As coisas ruim, a gente quer só para a gente.

A distância do dentista e os custos do tratamento, por impedirem que os escolares tenham atendimento odontológico, também causam sentimentos negativos nas mães. 
Entrevistador: Algum problema de dentes do (filho) ou da (filha) já atrapalhou o dia-a-dia da casa? Por que o (filho) já quebrou o dente, né?

Entrevistada n.10: Foi, mas eu tinha acesso à Faculdade, o problema era que tinha que ficar levando ele todo o dia, que era difícil. Mas hoje se você quiser conseguir as coisas, tem dificuldade mesmo. Mas a parte da tarde, eu ficava por conta dele na Universidade.

Entrevistador: Te tomou tempo.

Entrevistada n.10: Uns seis meses.

Entrevistador: Te tomou seis meses. Aí te atrapalhou em casa?

Entrevistada n.10: É, mas a gente fez por onde. Tem que cuidar deles, né. A gente, depois que a gente casa é que a gente dá valor para as mães da gente. Então, é que você vai ver que mais tarde você não vai ter valor também. (...) Quando eles tá pequeno você tem que fazer a sua parte, né. E eu fiz o que eu pude. O que estava ao meu alcance.

A fala dessa e de diversas outras mães revela que elas acham que têm um papel social a cumprir (mesmo que no futuro isso não seja valorizado), que é, dentre outros, de ser responsável pelas questões sanitárias em uma família. Essa liderança feminina nas questões da saúde em uma família já foi bem discutida na literatura. Existe, na sociedade, uma forte cobrança em relação ao que se considera papel da mãe. Especificamente no meio rural, as questões sanitárias têm sido identificadas como um atributo essencialmente feminino (Greenwood \& Cheers, 2003). A manutenção da saúde bucal é um desses papéis. As mães são fortemente cobradas em relação a essa obrigação social, sendo culpadas pelas condições de saúde bucal dos seus filhos (Wolf, 1998; Carneiro, 2001; Tezoquipa et al., 2001; Fernandes, 2002).

A dor de dente do filho, condição odontológica mais relatada pelas entrevistadas como fonte de problemas bucais, que a distância e a falta de condições financeiras não conseguem aliviar de imediato, gera ansiedade, frustrações e, conseqüentemente, pode repercutir na qualidade de vida das mães. Sarti (2001) comenta que a dor do outro gera, com mais ou menos intensidade, sentimentos de comoção e sofrimento. Além disso, outro estudo que avaliou o cotidiano de crianças hospitalizadas revelou sentimentos de culpa nas mães, sendo que as mesmas gostariam de estar no lugar do filho (Santos et al., 2001). Neste estudo, a dor de um filho gera sentimentos na mãe que confirmam a literatura consultada. Uma entrevistada reve- la o que sente por não conseguir tratar a dor de dente do seu filho.

Muito difícil, né. Fica achando ruim, né. Porque a gente fica querendo cuidar dos filhos da gente bem, né. Então é difícil, né. Fica achando ruim, né e tal. (...) Fica sentindo mal (riso) porque não tem condição de cuidar direito, né. (Entrevistada n. 21)

A presença do serviço de saúde bucal itinerante nas escolas é visto pelas mães como uma conquista de grande valor.

Entrevistador: Qual é o seu sentimento de ter um dentista aqui pertinho de você?

Entrevistada n. 19: É bom. O dente doeu, você arruma, se tiver marcado direitinho. É mais fácil, né. Você não precisa de passagem, né. Você não precisa de levantar cedo, ir para Itaúna, arrumar ficha para arrumar dente. É uma mão na roda.

No entanto, como o serviço não é fixo, há muitos momentos em que o atendimento no meio rural não existe. Neste momento a estabilidade desse grupo populacional é abalada e sua qualidade de vida também. Os itinerários terapêuticos incluem a procura pelo sindicato rural, faculdade de odontologia, serviços municipais de saúde e, em alguns casos, o atendimento privado. Em comunidades rurais canadense e australiana, os sentimentos das mães em relação à falta de acesso aos serviços de saúde são também negativos (Greenwood \& Cheers, 2003; Thurston \& Meadows, 2003).

Além disso, como os serviços municipais de saúde realizam procedimentos da atenção básica em saúde bucal, existe uma cobrança, na fala das entrevistadas, em relação à atenção secundária. Tratamentos endodônticos radicais, ortodontia e restaurações indiretas são demandas sentidas por essa população. No entanto, a realidade econômica desfavorável exclui as pessoas desse atendimento.

Entrevistador: O seu menino, o (nome do filho), ele já teve algum problema, assim, mais sério com os dentes?

Entrevistada n. 5: Não. Mas tá precisando de aparelho. Os dentes dele tá torto. Até a dentista lá do Sindicato (...) porque a gente mexe com o Sindicato Rural, né. Ela falou comigo, há mais de um ano, que precisa de pôr aparelho. Mas eu quero ver se eu consigo na ... como é que chama?

Entrevistador: Universidade?

Entrevistada n. 5: Universidade. Porque diz que lá a gente só paga os reajuste, né. Porque o aparelho sai mais barato. Porque para a gente colocar assim, não tem condição. 
Uma grande preocupação no meio rural é com a aparência da cavidade bucal dos filhos, ou seja, a questão da estética é considerada importante fator de saúde bucal para os entrevistados. Quando se aprofunda a análise sobre as preocupações centrais da estética, verifica-se que a questão mais relevante para os pais é a aparência dos dentes no convívio social.

Cada grupo social atribui ao ser humano as características consideradas adequadas, tanto do ponto de vista físico, quanto moral e intelectual. Ou seja a imagem que o indivíduo faz de si é construída no contato com o mundo, sendo sempre associada a um padrão imposto pelas exigências sociais. A família tem grande importância na construção desses valores. As pessoas são classificadas quanto à aparência, chegando, inclusive, a habilitá-las ou não para o mercado de trabalho. Em nossa sociedade a aparência é "superdimensionada" em detrimento de outros valores, o que torna as pessoas vulneráveis e com sentimentos de inferioridade quando não alcançam o padrão desenhado e inculcado pela mídia. Assim, um belo sorriso é um signo importante para a auto-apresentação. Quando um indivíduo apresenta uma alteração física visível, como, por exemplo, uma alteração estética socialmente não-aceita, o mesmo pode sofrer vários tipos de discriminações. Sendo considerado um estigmatizado, suas chances de vida social plena são fortemente diminuídas (Rodrigues, 1979; Goffman, 1988; Wolf, 1998).

Como afirma uma entrevistada:

(...) Porque na hora que precisar de conversar com uma pessoa, a primeira coisa que vai olhar é o sorriso, é os dentes, é a boca, né. (Entrevistada n. 26)

Ainda em relação à aparência dos dentes e seu impacto na qualidade de vida, os resultados do presente estudo confirmam os achados de Vargas (2002). A autora mostrou que problemas bucais visíveis, causados geralmente pela conseqüência da doença cárie dentária nos dentes anteriores, podem levar o indivíduo a uma situação estigmatizante. Uma mãe no nosso estudo ilustra bem essa situação.

De que adianta uma moça bonita... você que trabalha nesta área. Quantas pessoas, quantos rapazes, quantos amigos que abaixam a cabeça, nunca olham para você. Dá uma tristeza. Às vezes não tem nada a dever ao mundo mas vergonha dos dentes... torna ruim. (Entrevistada n. 8)

\section{Cuidados caseiros com saúde bucal}

As práticas de escovação e o controle da dieta foram relatados freqüentemente pelos entrevistados como importantes cuidados caseiros em relação à saúde bucal. Na grande maioria das famílias o processo de aquisição dos hábitos de higienização bucal inicia-se cedo na infância. Cabe aos pais realizarem, no máximo, as primeiras escovações dos filhos. Em muitos casos, os filhos copiam/imitam os atos realizados pelos pais.

Entrevistador: Como é que foi a primeira vez que a senhora escovou? Você escovou ou ela escovou sozinha?

Entrevistada n. 20: Não. Eu escovando e ela olhando. Depois ela foi e escovou, (...) do mesmo tipo que eu escovei, ela escovou o dela.

Depois os filhos são considerados independentes para essa atividade de vida diária. A partir desse momento, cabe aos pais apenas a exigência da atividade.

Entrevistador: Eles fazem (a escovação) sozinho?

Entrevistada n. 2: Aí eles fazem sozinho, porque ela já tá com sete anos e ele com quatro. Então todos os dois já têm capacidade de escovar sozinho. Aí eu só mando.

Alguns pais explicam que a causa da pouca participação nesse cuidado caseiro está associada às suas atividades do trabalho ou mesmo ao desconhecimento sobre as chamadas "técnicas de escovação". A realidade da vida dessa população é de grande importância na determinação dos seus hábitos de saúde.

Além do mais, muitas entrevistadas nunca receberam qualquer informação familiar sobre os cuidados bucais. Vamos entender as causas para essa situação.

Entrevistador: E quem ensinou para a senhora? (sobre escovação) Foi o dentista?

Entrevistada n. 7: Foi o dentista.

Entrevistador: Antes de a senhora ser orientada, a senhora fazia de outra forma?

Entrevistada n. 7: É. A gente já... assim... as mãe da gente já foi criada num tipo diferente. A minha mãe com quinze anos já tinha dentadura. Ela não sabia nem como explicar a cuidar de dente. Então, desde que ele começou a ir ao dentista... aprendeu com o dentista.

É equivocado exigir hábitos que não foram transmitidos pelas gerações passadas. Os programas de saúde bucal extremamente mutiladores, que influenciaram fortemente as características epidemiológicas brasileiras até a dé- 
cada de 1980 (Brasil, 1988; Pinto, 1997), contribuíram para essa situação.

Além disso, na nossa sociedade, as questões relativas à higiene são de foro íntimo. Até mesmo em uma família, a intimidade de tal processo é mantida. A transmissão de noções sobre higiene dos pais para os filhos é feita apenas quando os filhos estão sendo iniciados nesse processo (Rodrigues, 1979). Sabe-se por outro lado que crianças na faixa etária do presente estudo não apresentam coordenação motora suficiente para exercerem atividades de controle de placa bacteriana de forma eficaz. É necessária, assim, a ajuda dos pais (Buischi \& Axelsson, 1997). No entanto, atitudes educativas tradicionais e que apenas informem aos pais sobre essa necessidade, podem ser insuficientes para uma mudança de atitudes (Roux, 1994; Kemm, 2003; Pereira, 2003). O serviço de saúde bucal deve ter clareza dessas questões para que as atividades coletivas não sejam organizadas fora desse contexto.

A atividade de escovação não é vista pelas crianças como uma atividade interessante. $\mathrm{Na}$ verdade, os pais assumem que seus filhos e as crianças em geral, normalmente, têm preguiça de realizá-la.

Porque criança você já viu, né. É rara a criança que gosta de cuidar de dente. Pelo menos aqui por perto. (Entrevistada n. 7)

$\mathrm{Ou}$, de uma forma mais contundente, quando uma mãe me diz quem é seu filho:

$O$ (nome do filho) é uma criança normal, né: preguiçoso para escovar os dentes, né. (Entrevistada n. 29)

Em relação aos hábitos dietéticos caseiros, a maioria dos entrevistados é coerente com sua representação sobre o processo saúde-doença. Ou seja, se a alimentação é considerada tão importante para a manutenção da força do corpo, como mostrado anteriormente, seria uma incoerência qualquer tentativa de controle. Assim, os filhos são livres para comer o quanto quiserem e no momento que desejarem, caso as condições objetivas de vida assim permitirem.

Deixo comer. Não tem esse negócio de tantas em tantas horas. A gente nunca teve isso. Não sei se é certo ou errado, mas a gente nunca, sabe, deu conta de manter isso não. (...). Tá com fome come, bobagem esses trem de comer. (Entrevistada n. 18)

Os alimentos contendo sacarose são freqüentemente consumidos por essa população. Mas apenas para as balas e os chicletes, os denominados “imbondos", que "estragam" os dentes, há alguma tentativa de controle do consumo.
A relação entre sacarose e cárie dentária, bem definida na literatura, é um campo que deve ser trabalhado nas ações de promoção de saúde. O próprio ambiente escolar poderia ser um importante setor para a discussão sobre a alimentação e saúde, uma vez que o mesmo parece ter grande credibilidade junto da comunidade rural pesquisada.

O levantamento epidemiológico das condições dentárias nessa mesma população, cujos resultados foram apresentados em outro artigo, mostrou que há necessidades de tratamento para a doença cárie que o serviço de saúde bucal do município não conseguiu atender. Assim, as famílias relatam práticas caseiras em relação aos problemas bucais considerados mais importantes pelas mesmas: dor de dente, dentes claros. Em relação a essas práticas alternativas ao modelo biomédico, as mães afirmam que as conhecem, apesar de raramente admitirem sua utilização. A grande maioria relata que procura, principalmente em caso de dor de dente, o cirurgião-dentista na sede do município. A realização de bochechos com chás, gargarejos, benzição e até auto-medicação são conhecidos e relatados com bastante freqüência. Algumas entrevistadas revelam inclusive a influência dos seus antepassados na suas decisões terapêuticas, senão vejamos

Entrevistador: (...) o povo fala que tem alguma coisa boa para passar nos dentes, alguma folha...

Entrevistada n.15: Tem, isso tem... uma planta, um tomate, assim pequenininho que a minha mãe falou que é bom para limpar os dentes. E eu comprovei que é bom mesmo. (...) Esse tomate clareia os dentes.

Outra mãe revela.

Entrevistada n. 4: Chá de laranja-da-terra, chá de lima que eles falam que é bom para acalmar. Não valia de nada. Ele chorava a mesma coisa. Eu acho que chá e remédio para dor de dente não passa não. Se não é o dentista, não passa não. É só ilusão da gente.

Entrevistador: Sei. Mas usou o chazinho...

Entrevistada n. 4: Usou o chazinho, os remedinhos. Precisou.

Entrevistador: A senhora já sabia dos remedinhos? Quem te falou?

Entrevistada n. 4: A minha mãe, né. A minha mãe falou (risos) "vão fazer isso que é bom" e aí nós fazia e aí nada servia (mais risos).

É comum a utilização de recursos caseiros para os problemas de saúde em grupos populacionais. Especificamente em relação às necessi- 
dades de saúde bucal sentidas pela população, alguns trabalhos também têm identificado práticas caseiras. As explicações para tais condutas encontram respaldo na falta de acesso ao sistema de saúde, bem como em valores culturais construídos historicamente (Carneiro, 2001; Fernandes, 2002).

A utilização dos serviços de saúde oficiais pela classe trabalhadora é sempre cercada de conflitos. Ao mesmo tempo em que a população exige tratamento adequado neste sistema, ela o procura em outros locais. Essa procura por "terapias alternativas" revela que as pessoas resistem a serem tratadas como máquinas e buscam estratégias mais humanizadoras (Loyola, 1984; Paixão, 1986; Minayo, 1993).

\section{Conclusões e considerações finais}

As representações sociais das entrevistadas sobre saúde revelam que as condições objetivas de vida as determinam. É necessário um corpo forte para que o morador do meio rural possa trabalhar. A alimentação e a utilização dos serviços médicos desempenham funções de manutenção desse corpo, única fonte de subsistência para a maioria dos indivíduos em uma sociedade capitalista, estando associados às representações de saúde.

As representações sobre o processo saúde/doença bucal estão associadas às normas odontológicas de higiene e dieta. A cárie dentária é vista como uma experiência inevitável, mas a perda dentária, não. Antibióticos e saúde bucal têm uma associação inversa nas representações das mães entrevistadas. Todas essas representações expressam uma realidade de vida do grupo estudado.

A qualidade de vida das mães, mais do que a da família, é em parte afetada pelas condições de saúde dos escolares. É necessário comentar sobre a perversidade e a contradição do nosso sistema social em relação a essas mães. Por um lado, elas moram em locais distantes das "comodidades das cidades", sobrevivem em condições de grande privação econômica, trabalham em casa e algumas também, fora de casa e, muitas não vivenciaram na infância qualquer informação sobre saúde bucal. Por outro lado, há uma cobrança social em relação aos cuidados bucais do filhos, que elas introjetam e aceitam. Essa vivência contraditória causa sentimentos negativos (como a culpa) nessas mulheres e, conseqüentemente, queda na sua qua- lidade de vida. As políticas de promoção de saúde bucal, nessa realidade e no Brasil como um todo, devem considerar que as pessoas têm direitos sociais que devem ser respeitados. Através da vivência da cidadania plena, em que os sujeitos garantem os direitos já formalizados e, também, constroem novos direitos (Borges, 2003), é que as populações poderão garantir condições sociais, econômicas e ambientais para tornar as escolhas saudáveis, as escolhas mais fáceis. Ou dito de outra forma, é necessário haver "incremento de poder" (empowerment) comunitário e pessoal, através do desenvolvimento de habilidades e atitudes que levem à aquisição de poder técnico e político em prol da saúde (Pereira, 2003). Na realidade dessas mulheres entrevistadas, verifica-se claramente que, apesar das mesmas apresentarem informações sobre o cuidado bucal e desejarem "cuidar dos filhos direito", uma complexa rede de fatores sociais, econômicos, culturais, etc., não favorece a promoção de saúde. Desta forma, medidas técnicas, preventivas ou apenas educativas planejadas para as populações não serão capazes de melhorar o quadro epidemiológico de saúde bucal identificado no meio rural itaunense. A implementação de ações intersetoriais poderia ser estimulada a fim de criar condições de vida e trabalho que conduzam à saúde e bem-estar. Além disso, o planejamento das ações coletivas de saúde bucal deve ser construído com a participação da população rural (WHO, 1996; Moysés \& Watt, 2000; Watt, 2002).

É interessante, também, que os profissionais de saúde bucal que lidam com populações rurais, seja no contato direto seja no planejamento das ações coletivas, apresentem sensibilidade e conhecimento científico que extrapolem a explicação biomédica.

$\mathrm{O}$ entendimento das representações sociais, que são peculiares aos moradores do meio rural, poderá levar a um planejamento das ações de saúde menos alienantes e mais humanas. No mesmo sentido, as pessoas devem ser consultadas e escutadas nas suas demandas de saúde. Conseqüentemente, espera-se que cada vez mais as políticas de saúde bucal coletiva adotem métodos qualitativos visando ações de saúde coletiva construídas em conjunto com os sujeitos das ações. 


\section{Colaboradores}

MHNG Abreu trabalhou na construção do referencial teórico-metodológico, entrevistas, análise de conteúdo, redação do artigo; IA Pordeus, na construção do referencial teórico-metodológico, orientação na análise de conteúdo e redação do artigo e CM Modena, na construção do referencial teórico-metodológico, orientação na análise de conteúdo e redação do artigo.

\section{Agradecimentos}

Os autores agradecem a ajuda financeira recebida do Conselho Nacional de Desenvolvimento Científico e Tecnológico $(\mathrm{CNPq})$ e da Fundação de Amparo à Pesquisa do Estado de Minas Gerais (FAPEMIG). Agradecimentos devem ser dirigidos também à Prefeitura de Itaúna pela colaboração na realização do trabalho. Os autores agradecem aos revisores do presente trabalho pela qualidade dos comentários e pelas modificações sugeridas.

\section{Referências bibliográficas}

Abreu MHNG 2004. Dimensões epidemiológicas da saúde bucal da população rural de Itaúna, Minas Gerais, 2002. Tese de doutorado. Escola de Veterinária, Universidade Federal de Minas Gerais, Belo Horizonte.

Amaral LA et al. 2003. Água de consumo humano como fator de risco à saúde em propriedades rurais. Revista de Saúde Pública 37(4):510-514.

Andrade CMJ 1996. Representações de saúde-doença e alternativas terapêuticas em bairros da periferia de Belo Horizonte (1994-1996). Dissertação de mestrado. Escola de Veterinária, Universidade Federal de Minas Gerais, Belo Horizonte.

Andrioni JN, Benfatti SV, Russo MC \& Toledo OA 1969. Prevalência de gengivite e de cárie dental. Revista Brasileira de Odontologia 26(155):5-10.

Auad S \& Pordeus IA 1999. Nutrição e sua influência nos processos de odontogênese, erupção e desenvolvimento da cárie dentária. Revista do CROMG 5(3):151-155.

Bardin L 1977. Análise de conteúdo. Edições 70, Lisboa, $230 \mathrm{pp}$

Bernd B et al. 1992. Percepção popular sobre saúde bucal: o caso das gestantes do Valão. Saúde em Debate 34:33-39.

Bijella MFTB \& Bijella VT 1970. Prevalência de cárie dental em escolares da zona rural de 12 municípios da região de Bauru. Revista Brasileira de Odontologia 27(163):133-138.

Boltanski L 1989. As classes sociais e o corpo. (3a ed.). Graal, Rio de Janeiro.

Borges EM 2003. Programa Bolsa-Escola de Belo Horizonte: limites e possibilidades de uma politica de inclusão social. Dissertação de mestrado. Escola de Governo, Fundação João Pinheiro, Belo Horizonte.

Brasil. Ministério da Saúde 1988. Levantamento epidemiológico em saúde bucal: Brasil, zona urbana, 1986. Cen- tro de Documentação do Ministério da Saúde, Brasília.

Breilh J 1991. Epidemiologia. Economia, politica e saúde. Editora Unesp, São Paulo.

Brindle R, Wilkinson D, Harrison A, Connolly C \& Cleaton-Jones P 2000. Oral health in Hlabisa, KwaZulu/Natal - a rural school and community based survey. International Dental Journal 50(1):13-20.

Buischi YP \& Axelsson P 1997. Controle mecânico de placa dental realizado pelo paciente, pp. 115-127. In L Kriger. Aboprev. Promoção de saúde bucal. Artes Médicas, São Paulo.

Capra F 1989. O ponto de mutação. A ciência, a sociedade e a cultura emergente. Cultrix, São Paulo.

Carneiro AMO 2001. Percepções em Saúde bucal: valores, atitudes e problemas de um grupo de pessoas residentes na área rural de Brazilândia - DF. Dissertação de mestrado. Faculdade de Odontologia, Universidade Federal de Minas Gerais, Belo Horizonte.

Carvalho de Oliveira AM \& Tavares D 1981. Prevalência da cárie dentária em primeiros molares permanentes de escolares novos - zona rural da Grande Florianópolis - SC. Revista da Faculdade de Odontologia da UFBa 1(1):39-55.

Cavalini SFS 2000. Um estudo sobre a implicação da relação pais-filhos na inibição intelectual. Dissertação de mestrado. Universidade São Marcos, São Paulo.

Dini EL \& Silva SRC 1994. Prevalence of caries and dental care status of schoolchildren from urban and rural areas in Araraquara, SP, Brazil. International Dental Journal 44(6):613-616.

Fernandes MLMF 2002. Análise comparativa das percepções em saúde bucal de adolescentes grávidas e não grávidas: um ponto de partida para a promoção em 
saúde bucal. Dissertação de mestrado. Faculdade de Odontologia, Universidade Federal de Minas Gerais, Belo Horizonte.

Ferreira AAA 2002. Representações sociais da necessidade de cuidados bucais: um estudo com habitantes do bairro de Cidade da Esperança - Natal/RN. Dissertação de mestrado, Centro de Ciências da Saúde, Universidade Federal do Rio Grande do Norte, Natal.

Furtado A, Traebert JL \& Marcenes WS 1999. Prevalência de doenças bucais e necessidades de tratamento em Capão Alto, Santa Catarina. Revista da ABO Nacional 7(4):226-230.

Goffman E 1988. Estigma. Notas sobre a manipulação da identidade deteriorada. (4a ed.). Editora Guanabara, Rio de Janeiro.

Greenwood G \& Cheers B 2003. Women, isolation and bush babies. Rural and Remote Health 2. Disponível em $<$ http://rrh.deakin.edu.au $>$.

Guimarães MM \& Marcos B 1996. Expectativa de perda de dente em diferentes classes sociais. Revista do CROMG 2(1):16-20.

Gustafsson BE et al. 1954. The effect of different levels of carbohydrate intake on caries activity in 436 individuals observed for five years. Acta Odontologica Scandinava 11:232-364.

Kemm J 2003. Health education: a case for resuscitation. Public Health 117(2):106-111.

Kwan SYL \& Holmes MAM 1999. An exploration of oral health beliefs and attitudes of Chinese in West Yorkshire: a qualitative investigation. Health Education Research 14(4):453-460.

Locker D, Clarke M \& Payne B 2000. Self-perceived oral health status, psychological well-being, and life satisfaction in an older adult population. Journal of Dental Research 79(4):970-975.

Loyola MA 1984. Médicos e curandeiros. Conflito social e saúde. Difel, São Paulo.

Makowiecky N \& Silva RHH 1981. Prevalência de cárie dentária em 277 escolares, alunos novos da 1a série do 10 grau, de sete a dez anos de idade, ambos os sexos, de 35 escolas públicas localizadas na zona rural da região da Grande Florianópolis, estado de Santa Catarina. Revista Catarinense de Odontologia 8(2):26-31.

Mallison S 2002. Listening to respondents: a qualitative assessment of the Short-Form 36 Health Status Questionnaire. Social Science and Medicine 54(1):11-21.

Marcos B et al. 1977. Doença periodontal e cárie dental na população brasileira. Necessidade de tratamento, atenção odontológica e formação profissional. Arquivos do Centro de Estudos do Curso de Odontologia 14(1/2):71-84

Marques DE, Rink MCM, Loureiro RMT \& Silva VC 1986. Levantamento epidemiológico de cárie dentária na zona rural de Uberlândia - Minas Gerais. Contribuição para um modelo de programa de saúde bucal. Revista do Centro de Ciências Biomédicas da Universidade Federal de Uberlândia 2(1):33-38.

Marsiglia RG, Barata RC \& Spinelli SP 1990. Determinação social do processo epidêmico, pp. 127-147. In Abrasco. Textos de apoio. Epidemiologia I. (2a ed.). ENSP, Rio de Janeiro.

Mendonça TC 2001. Mutilação dentária: concepções de trabalhadores sobre a responsabilidade pela perda dentária. Cadernos de Saúde Pública 17(6):1545-1547.

Minayo MCS 1988. Saúde-doença: uma concepcão popular de etiologia. Cadernos de Saúde Pública 4(4):63-381.
Minayo MCS 1993. O desafio do conhecimento. Pesquisa qualitativa em saúde. Hucitec-Abrasco, Rio de Janeiro.

Minayo MCS 1994. Quantitativo e qualitativo em indicadores de saúde: revendo conceitos, pp. 25-33. In MFL Costa \& RP Souza. Qualidade de vida: compromisso histórico da epidemiologia. Coopmed, Belo Horizonte.

Mota S 1999. Saneamento, pp. 405-430. In MZ Rouquayrol \& N Almeida Filho. Epidemiologia e saúde. (5a ed.). Medsi, Rio de Janeiro.

Moysés ST \& Watt R 2000. Promoção de saúde: definições, pp. 3-22. In Y Buischi. Promoção de saúde bucal na clínica odontológica. Artes Médicas, São Paulo.

Nadanovsky P 2000. O declínio da cárie, pp. 341-351. In VG Pinto. Saúde bucal coletiva. (4a ed.). Editora Santos, São Paulo.

Nations MK \& Nuto SAS 2002. "Tooth worms", poverty tattoos and dental care conflicts in Northeast Brazil. Social Science and Medicine 54(2):229-244.

Nevillle BW, Damm DD, Allen, CM \& Bouquot \& JE 2002. Defeitos do desenvolvimento da região maxilofacial e oral pp. 49-103. In BW Nevilll, DD Damm, CM Allen $\&$ Bouquot. Patologia oral e maxilofacial. (2a ed.). Guanabara Koogan, Rio de Janeiro.

Oliveira CMB, Assis DF \& Ferreira EF 1995. Avaliação da fluoretação da água de abastecimento público de Belo Horizonte, MG, após 18 anos. Revista do CROMG 1(2):62-66.

Paixão HH 1986. Saúde e doença: um estudo de representação social. Arquivos do Centro de Estudos do Curso de Odontologia 23(1/2):9-17.

Paixão HH, Pordeus IA \& Ferreira EF 1995. Saúde e doença bucal: concepções e contradições. IV Encontro de Pesquisa da Faculdade de Odontologia da UFMG.

Pereira ALF 2003. Pedagogical approaches and educational practices in health sciences. Cadernos de Saúde Pública 19(5):1527-1534

Perini E 1998. O abandono do tratamento da tuberculose: transgredindo regras, banalizando conceitos. Tese de doutorado. Escola de Veterinária, Universidade Federal de Minas Gerais, Belo Horizonte.

Pinto VG 1997. Epidemiologia das doenças bucais no Brasil, pp. 27-41. In L Kriger. Aboprev. Promoção de saúde bucal. Artes Médicas, São Paulo.

Pordeus IA 1991. Intra-family patterns of dental health status and behaviors. A study of Brazilian families. Tese de doutorado. University College of London, Londres.

Prefeitura da Cidade de Itaúna - PCI 2000. Plano Municipal de Saúde 2000/2003. Itaúna.

Reisine ST 1988. The impact of dental conditions on social functioning and the quality of life. Annual Review of Public Health 9:1-19.

Rodrigues JC 1979. O tabu do corpo. Achiamé, Rio de Janeiro.

Rouquayrol MZ \& Goldbaum M 1999. Epidemiologia, história natural e prevenção de doenças, pp. 15-30. In MZ Rouquayrol \& N Almeida Filho. Epidemiologia e saúde. (5a ed.). Medsi, Rio de Janeiro.

Roux GI 1994. La prevención de comportamientos de riesgo y la promoción de estilos de vida saluble en el desarrolo de la salud. Educ Med Salud 28(2):223-233.

Ruffino Neto A 1994. Qualidade de vida: compromisso histórico da epidemiologia, pp. 11-18. In MFL Costa \& RP Souza. Qualidade de vida: compromisso histórico da epidemiologia. Coopmed, Belo Horizonte.

Sampaio FC, Hossain MN, Von Der Fehr FR \& Arneberg 
P 2000. Dental caries and sugar intake of children from rural areas with different water fluoride levels in Paraiba, Brazil. Community Dentistry and Oral Epidemiology 28(4):307-313.

Santos AF et al. 2001. O cotidiano da mãe com seu filho hospitalizado: uma contribuição para a enfermagem pediátrica. Escola Anna Nery Revista de Enfermagem 5(3):325-334,.

Santos SR 1999. Métodos quantitativos e qualitativos na pesquisa biomédica. Jornal de Pediatria 75(6):401-406.

Sarti CA 2001. A dor, o indivíduo e a cultura. Saúde e Sociedade 10(1):1-10.

Sevalho G 1993. Uma abordagem histórica das representações sociais de saúde e doença. Cadernos de Saúde Pública 9(3):349-363.

Sheiham A 2000. A determinação de necessidades de tratamento odontológico: um abordagem social, pp. 222-250. In VG Pinto. Saúde bucal coletiva. (4a ed.). Santos, São Paulo.

Tezoquipa IH, Monreal MLA \& Santiago RV 2001. El cuidado a la salud en el ámbito doméstico: interacción social y vida cotidiana. Revista de Saúde Pública 35(5):443-450.

Thurston WE \& Meadows LM 2003. Rurality and health: perspectives of mid-life women. Rural and Remote Health 3. Disponível em <http://rrh.deakin.edu.au $>$.

Triviños ANS 1987. Introdução à pesquisa em ciências sociais: a pesquisa qualitativa em educação. Ática, São Paulo.
Vargas AMD 2002. Políticas públicas e qualidade de vida: um estudo sobre a perda dentária. Tese de doutorado. Escola de Veterinária, Universidade Federal de Minas Gerais, Belo Horizonte.

Vicente CM 1998. O direito à convivência familiar e comunitária: uma política de manutenção do vínculo, pp. 47-59. In SM Kaloustian. Família brasileira: a base de tudo. (3a ed.). Cortez Editora-Unicef, São Paulo.

Wannmacher L \& Ferreira MBC 1999. Farmacologia clinica para dentistas. (2a ed.). Editora Guanabara Koogan, Rio de Janeiro.

Watt RG 2002. Emerging theories into the social determinants of health: implications for oral health promotion. Community Dentistry and Oral Epidemiology 30(4):241-247.

WHO 1996. Charte D’ Ottawa. La Santé de 'Homme 325:3-5.

WHOQOL Group 1995. The World Health Organization Quality of Life Assesment (WHOQOL): position paper from the World Health Organization. Social Science and Medicine 41(10):403-409.

Wolf SMR 1998. O significado psicológico da perda dos dentes em sujeitos adultos. Revista da APCD 52(4): 307-315.

Artigo apresentado em 12/4/2004

Aprovado em 20/6/2004

Versão final apresentada em 22/7/2004 